\title{
Desempenho e características de carcaça de suínos dos 20 aos 50kg recebendo rações com reduzido teor de proteína bruta e diferentes níveis de lisina digestível verdadeira
}

\author{
Performance and carcass characteristics of swine from 20 to $50 \mathrm{~kg}$ receiving diets with reduced \\ crude protein and different levels of true digestible lysine
}

\author{
Márcio Gilberto Zangeronimo ${ }^{\mathrm{I}^{*}}$ Elias Tadeu Fialho ${ }^{\mathrm{II}}$ José Augusto de Freitas Lima $^{\mathrm{II}}$ \\ Lúcio Vilela Carneiro Girão ${ }^{\text {II }}$ Níkolas de Oliveira Amaral ${ }^{\text {II }}$ Hebert Silveira ${ }^{\text {II }}$
}

\section{RESUMO}

O objetivo deste trabalho foi avaliar diferentes níveis de lisina digestível (LISD), em rações com reduzido teor de proteína bruta (PB), por meio do desempenho e das características de carcaça de suínos dos 20 aos 50kg. Foram utilizados 40 suínos machos, castrados, de elevado potencial para ganho de carne (peso inicial de 22,5 $\pm 1,4 \mathrm{~kg}$ e final de $47,8 \pm 3,4 \mathrm{~kg})$, distribuídos em delineamento em blocos casualizados, com cinco tratamentos (quatro níveis de LISD 0,7; 0,9; 1,1 e 1,3\% - em rações com 14\% PB e um tratamentocontrole, formulado de acordo com as tabelas brasileiras, com $1,03 \%$ LISD e $18 \%$ de PB) e quatro repetições, durante 31 dias. Não houve diferença $(P>0,05)$ entre os níveis de LISD, em rações com $14 \%$ PB para o ganho de peso diário; entretanto, apenas o nível $0,7 \%$ de lisina foi diferente em relação ao tratamento-controle. Não houve diferença $(P>0,05) \mathrm{com}$ relação ao consumo, mas houve um efeito linear crescente $(P<0,05)$ dos níveis de lisina na conversão alimentar em rações com reduzido teor de $P B$. A eficiência de utilização de lisina, para ganho de peso, diminuiu $(P<0,05)$ linearmente com o aumento desse aminoácido. Houve efeito quadrático para rendimento de carcaça, área de olho de lombo e relação carne:gordura, sendo 1,03; 1,00 e 1,09\% os respectivos níveis de LISD que proporcionaram melhores resultados nesse nível de PB. Com relação ao tratamento-controle, os níveis de $0,9 \%$ e 1,1\% de LISD apresentaram maior rendimento de carcaça. Não houve diferença $(P>0,05)$ para espessura de toucinho. Conclui-se que o nível de 1,1\% de LISD em rações com reduzido teor de PB melhora a qualidade da carcaça, sem afetar o desempenho.

Palavras-chave: aminoácido livre, exigência nutricional, nutrição animal, qualidade de carcaça.

\begin{abstract}
The objective of this research was to evaluate the different levels of true digestible lysine (TDL) in diets with reduced crude protein (CP) level through to performance and carcass characteristics of pigs from 20 to $50 \mathrm{~kg}$. Forty barrows with high performance (initial weight of $22.50 \pm 1.4 \mathrm{~kg}$ and final of $47.8 \pm 3.4 \mathrm{~kg}$ ), distributed in randomized block design with five treatments (four levels of TDL - 0.7, 0.9, 1.1 and 1.3\% - in $14 \%$ CP diets - and a control treatment, formulated in accordance to Brazilian Tables, with $1.03 \%$ of TDL and $18 \%$ $C P)$ and four replications during 31 days were utilized. There were no differences $(P>0.05)$ between levels of TDL in diets with $14 \%$ CP for average daily gain; however, just the level of $0.7 \%$ of TDL was different of control treatment. There was no difference $(P>0.05)$ on feed intake, but there was crescent linear effect $(P<0.05)$ of the TDL levels on feed conversion in reduced $C P$ diets. The lysine utilized efficiency to weight gain decrease $(P<0.05)$ linearly with the increase of this amino acid. There was quadratic effect to carcass yield, Longissimus muscle area and meat:fat relation being 1.03; 1.00 and 1.09\% the respective levels of TDL that resulted the best results in this CP level. With regard to the control treatment the levels of 0.9 and $1.1 \%$ of TDL shown bigger carcass yield. There was no difference $(P>0.05)$ to backfat thickness. It was conclude that the level of $1.1 \%$ TDL in diets with reduced CP increase carcass yield without to modify the performance.
\end{abstract}

Key words: animal nutrition, carcass quality crystalline amino acid, nutritional requirements.

\section{INTRODUÇÃO}

Visando satisfazer a demanda do mercado consumidor de carne suína, as empresas de

IDepartamento de Medicina Veterinária, Universidade Federal de Lavras (UFLA), CP 3037, 37200-000, Lavras, MG, Brasil.

E-mail: marciozan78@yahoo.com.br. *Autor para correspondência.

IIDepartamento de Zootecnia, UFLA, Lavras, MG, Brasil. 
melhoramento genético têm se preocupado com a melhoria da qualidade de carcaça dos animais abatidos, objetivando aumento da produção de carne e redução no teor de gordura. Dessa forma, recursos nutricionais, principalmente relacionados à formulação de dietas, têm sido desenvolvidos nos últimos anos com o intuito de acompanhar esse crescente avanço genético dos suínos utilizados na suinocultura industrial.

O conceito de proteína ideal tem sido cada vez mais preconizado na nutrição de suínos, uma vez que está relacionado ao melhor aproveitamento dos nutrientes (KERR et al., 2003; OLIVEIRA et al., 2006). Além disso, a adequada suplementação dietética com aminoácidos sintéticos está diretamente ligada à deposição de tecido muscular, melhorando o desempenho e as características de carcaça (OLIVEIRA et al., 2003). Também é proposto que todos os aminoácidos podem ser relacionados à lisina e, se a exigência desse aminoácido varia, devido ao genótipo ou peso vivo, o padrão dos demais aminoácidos alterase proporcionalmente, mantendo uma relação constante com este aminoácido referência (FIRMAN \& BOLING, 1998).

Entretanto, há evidências de que a absorção de aminoácidos sintéticos seja mais rápida, quando comparada à absorção de aminoácidos presentes nas proteínas dos alimentos (PARTRIDGE et al., 1985) e que isso seria responsável por um desequilíbrio nos sítios de síntese protéica (BATTERHAM \& BAYLEY, 1989). Além disso, o processo competitivo pelos sítios de absorção, gerado pelos aminoácidos na forma livre, podem tornar outros aminoácidos limitantes, mesmo estando em quantidades adequadas na dieta. Isso explicaria o menor desempenho (DE LA LLATA et al., 2002) e o aumento da quantidade de gordura na carcaça (LE BELLEGO et al., 2001), observado, muitas vezes, em suínos alimentados com rações, contendo reduzido teor de proteína bruta.

Dessa forma, o uso de aminoácidos cristalinos tem gerado uma série de dúvidas, principalmente em se tratando da relação aminoácidos essenciais:não essenciais (OLIVEIRA et al., 2006), uma vez que, na prática, apenas alguns aminoácidos (lisina, metionina, treonina e glutamina, por exemplo) são utilizados em rações que contêm níveis reduzidos de proteína (ZANGERONIMO et al., 2006).

Assim, o objetivo deste trabalho foi avaliar diferentes níveis de lisina digestível verdadeira, em rações com diferentes teores de proteína bruta para suínos dos 20 aos $50 \mathrm{~kg}$ por meio do desempenho e das características de carcaça.

\section{MATERIAL E MÉTODOS}

O experimento foi conduzido no Setor de Suinocultura do Departamento de Zootecnia da Universidade Federal de Lavras, em Lavras, região Sul do Estado de Minas Gerais. Foram utilizados 40 suínos machos castrados (Agroceres PIC) com peso inicial de $22,5 \pm 1,4 \mathrm{~kg}$ e final de $47,8 \pm 3,4 \mathrm{~kg}$, alojados em grupos de dois (parcela experimental), em galpão de crescimento com baias, com piso de concreto (2,3 x $1,5 \mathrm{~m})$, dotadas de comedouros semiautomáticos e bebedouro tipo chupeta, durante um período experimental de 31 dias. As temperaturas foram controladas através de cortinas nas laterais do galpão, sendo registradas temperaturas mínima, média e máxima de $21,4 \pm 2,0^{\circ} \mathrm{C} ; 23,8 \pm 2,0^{\circ} \mathrm{C}$ e $26,4 \pm 1,9^{\circ} \mathrm{C}$, respectivamente. A limpeza das baias foi feita diariamente, pela manhã e pela tarde.

Foi adotado o delineamento experimental em blocos casualizados, com cinco tratamentos e quatro repetições, sendo os blocos constituídos pelo peso inicial dos animais. Para as variáveis de desempenho, a unidade experimental foi representada por dois animais e, para as variáveis de carcaça, a unidade experimental foi constituída por um animal, definido por sorteio.

As rações foram formuladas à base de milho e farelo de soja para conterem 3230 $\mathrm{kcal} \mathrm{kg}^{-1}$ de energia metabolizável, $14 \%$ de proteína bruta e diferentes níveis de lisina digestível verdadeira $(0,7 ; 0,9 ; 1,1$ e 1,3\%), sendo comparadas a uma ração convencional, contendo 1,03\%, 3230 kcal kg-1 e 18\% de lisina digestível verdadeira, energia metabolizável e proteína bruta, respectivamente. Os níveis de metionina e treonina foram ajustados em função da lisina, de acordo com a relação aminoacídica proposta por ROSTAGNO et al. (2005). As dietas experimentais estão apresentadas na tabela 1 .

Os animais foram pesados no início e no final do experimento. As rações fornecidas e as sobras também foram diariamente pesadas para determinação do consumo. A conversão alimentar foi obtida pela relação entre o consumo de ração e o ganho de peso durante o período experimental. A eficiência de utilização da lisina para ganho de peso foi determinada pela relação lisina consumida (em gramas) pelo ganho de peso (em quilos) no período experimental.

Ao final do experimento, após jejum sólido por 12 horas, um animal de cada baia foi escolhido a partir de sorteio e abatido para avaliações de carcaça. Após dessensibilização elétrica, os animais foram sangrados e eviscerados, sendo as carcaças preparadas, sem a cabeça e as patas, pesadas antes e após o resfriamento, durante 24 horas. A área de olho de lombo e espessura de toucinho no ponto P2 foram 
Tabela 1 - Composição centesimal e calculada das dietas experimentais.

\begin{tabular}{|c|c|c|c|c|c|}
\hline \multirow{2}{*}{ Ingredientes } & 14 & 14 & 14 & 14 & 18 \\
\hline & 0,7 & 0,9 & 1,1 & 1,3 & 1,03 \\
\hline Milho & 66,0 & 66,0 & 66,0 & 66,0 & 64,0 \\
\hline Farelo de soja & 19,0 & 19,0 & 19,0 & 19,0 & 28,0 \\
\hline Óleo de soja & 3,5 & 3,5 & 3,5 & 3,5 & 2,5 \\
\hline Amido & 4,0 & 4,0 & 4,0 & 4,0 & 0,0 \\
\hline Fosfato bicálcico & 1,700 & 1,700 & 1,700 & 1,700 & 1,710 \\
\hline Calcáreo & 0,385 & 0,385 & 0,385 & 0,385 & 0,385 \\
\hline Sal & 0,300 & 0,300 & 0,300 & 0,300 & 0,300 \\
\hline Bicarbonato de sódio & 0,260 & 0,370 & 0,501 & 0,640 & 0,000 \\
\hline Suplemento vitamínico ${ }^{1}$ & 0,100 & 0,100 & 0,100 & 0,100 & 0,100 \\
\hline Suplemento mineral ${ }^{2}$ & 0,100 & 0,100 & 0,100 & 0,100 & 0,100 \\
\hline L-lisina $\mathrm{HCl}$ & 0,166 & 0,420 & 0,705 & 0,991 & 0,300 \\
\hline DL-Metionina & 0,000 & 0,060 & 0,120 & 0,180 & 0,040 \\
\hline L-Treonina & 0,000 & 0,120 & 0,250 & 0,380 & 0,060 \\
\hline Antibiótico $^{3}$ & 0,050 & 0,050 & 0,050 & 0,050 & 0,050 \\
\hline Caolim & 4,400 & 3,900 & 3,300 & 2,700 & 2,200 \\
\hline Total & 100 & 100 & 100 & 100 & 100 \\
\hline \multicolumn{6}{|l|}{ Valores calculados: } \\
\hline Protetína bruta (\%) & 14,0 & 14,0 & 14,0 & 14,0 & 18,0 \\
\hline Energia metabolizável (kcal) & 3230 & 3230 & 3230 & 3230 & 3230 \\
\hline Cálcio (\%) & 0,630 & 0,630 & 0,630 & 0,630 & 0,650 \\
\hline Fósforo disponível (\%) & 0,332 & 0,332 & 0,332 & 0,332 & 0,332 \\
\hline Lisina digestível (\%) & 0,700 & 0,900 & 1,100 & 1,300 & 1,030 \\
\hline Metionina digestível (\%) & 0,211 & 0,271 & 0,331 & 0,391 & 0,301 \\
\hline Treonina digestível (\%) & 0,455 & 0,585 & 0,716 & 0,846 & 0,660 \\
\hline
\end{tabular}

${ }^{1}$ Suplemento vitamínico contendo: vitamina A, 8.000.000UI; vitamina D3, 1.200.000UI; vitamina E, 20g; vitamina K3, 2.500mg; vitamina B1, 1.000mg; riboflavina (B2), 4.000mg; piridoxina (B6), 2.000mg; vitamina B12, 20.000mcg; niacina, 25.000mg; ácido pantotênico, 10g; ácido fólico, 600mg; biotina, 50mg; vitamina C, 50g; antioxidante, 125mg e excipiente q.s.q. 1000g.

${ }^{2}$ Suplemento mineral contendo, por kg do produto: selênio, 500mg; ferro, $180 \mathrm{~g}$; cobre, 20g; manganês, $80 \mathrm{~g}$; zinco, 140g; iodo, 4g; cobalto, 4 g e excipiente q.s.q. $1000 \mathrm{~g}$.

${ }^{3}$ Tylan $S^{\circledR} 100$ (Fosfato de Tilosina e Sulfametazina).

medidas no dia da pesagem da carcaça fria, na altura da última costela, na região de inserção da última vértebra torácica com a primeira lombar. No caso da área de olho de lombo, mediu-se apenas o músculo Longissumus dorsi e a espessura de toucinho tomada em três pontos, 6, 9 e 12cm da linha de corte dorsal da carcaça, de acordo com a ABCS (1973). Posteriormente, foi determinada a relação carne:gordura na carcaça, de acordo com a equação proposta por BRIDI \& SILVA (2006):

$$
\text { RCG = AOL / AGS, em que: }
$$

RCG = relação carne/gordura;

$\mathrm{AOL}=$ área de olho de lombo $\left(\mathrm{cm}^{2}\right)$;

AGS = área da gordura subcutânea $\left(\mathrm{cm}^{2}\right)$.

Os dados obtidos foram submetidos à análise de variância, com uso do teste Dunnett a 5\% para comparar o tratamento-controle com os demais e com a análise de regressão, quando os níveis de lisina foram comparados entre si em rações com reduzido teor de proteína bruta. Todas as análises foram feitas com uso do programa estatístico Sisvar 4.3 (FERREIRA, 2000).

\section{RESULTADOS E DISCUSSÃO}

Os resultados para ganho de peso médio diário (GPMD), consumo de ração médio diário (CRMD), conversão alimentar (CA), eficiência de utilização de lisina (EULIS), rendimento de carcaça (RC), área de olho de lombo (AOL), espessura de toucinho (ET) e relação carne:gordura (RCG) estão na tabela 2.

Ciência Rural, v.39, n.5, ago, 2009. 
Tabela 2 - Ganho de peso médio diário (GPMD), consumo de ração médio diário (CRMD), conversão alimentar (CA), eficiência de utilização de lisina (EULIS), rendimento de carcaça (RC), área de olho de lombo (AOL), espessura de toucinho (ET) e relação carne:gordura (RCG) de suínos abatidos na fase de crescimento recebendo rações contendo diferentes níveis de lisina e proteína bruta.

\begin{tabular}{|c|c|c|c|c|c|c|}
\hline \multirow{2}{*}{ Variável analisada } & \multicolumn{4}{|c|}{----------Nível de lisina digestível (\%)---------- } & \multirow{2}{*}{ Controle $^{\dagger}$} & \multirow{2}{*}{$\mathrm{CV}(\%)$} \\
\hline & 0,7 & 0,9 & 1,1 & 1,3 & & \\
\hline GPMD (g dia $\left.{ }^{-1}\right)$ & $777^{*}$ & 860 & 800 & 808 & 878 & 7,99 \\
\hline CRMD (g dia $\left.{ }^{-1}\right)$ & 1785 & 1829 & 1705 & 1706 & 1894 & 7,53 \\
\hline $\mathrm{CA}^{1}$ & 2,31 & 2,12 & 2,13 & 2,11 & 2,16 & 5,03 \\
\hline EULIS $^{2}$ (g lisina digesível consumida/ganho de peso) & 51,4 & 42,8 & 33,8 & 28,3 & 37,9 & 5,56 \\
\hline $\mathrm{RC}(\%)^{3}$ & 76,7 & $78,8^{*}$ & $79,0 *$ & 77,6 & 77 & 1,12 \\
\hline $\operatorname{AOL}\left(\mathrm{cm}^{2}\right)^{3}$ & $24,7^{*}$ & $26,5^{*}$ & 28,8 & $24,0 *$ & 30,3 & 5,05 \\
\hline $\mathrm{ET}(\mathrm{mm})$ & 9,45 & 9,44 & 8,78 & 8,78 & 10,17 & 10,82 \\
\hline $\mathrm{RCG}^{1}$ & $2,289 *$ & $2,702^{*}$ & $4,019 *$ & 2,958 & 3,678 & 11,4 \\
\hline
\end{tabular}

${ }^{\dagger}$ Dieta contendo 18\% PB e 1,03\% de lisina digestível.

* Difere do tratamento controle pelo teste Dunnett $(\mathrm{P}<0,05)$.

${ }^{1}$ Regressão linear significativa $(\mathrm{P}<0,05)$ dos níveis de lisina digestível: $\mathrm{y}=-0,059 \mathrm{x}+2,315 \mathrm{R}^{2}=0,63$.

${ }^{2}$ Regressão linear significativa $(\mathrm{P}<0,01)$ dos níveis de lisina digestível: $\mathrm{y}=-7,83 \mathrm{x}+58,65 \mathrm{R}^{2}=0,98$.

${ }^{3}$ Regressão quadrática significativa $(\mathrm{P}<0,05)$ dos níveis de lisina digestível.

Não houve diferença ( $\mathrm{P}>0,05)$ entre os níveis de LISD em rações com 14\% PB para o ganho de peso diário. Esse resultado foi similar ao encontrado por GASPAROTTO et al. (2001) que, trabalhando com suínos melhorados ( 24 a $45 \mathrm{~kg}$ de peso vivo), não encontraram efeitos dos níveis de lisina digestível verdadeira, ao utilizarem níveis variando entre 0,75 a $1,20 \%$. Por outro lado, TRINDADE NETO et al. (2005) observaram efeito linear crescente dos níveis de lisina total $(0,83$ a $1,23 \%)$ sobre o ganho de peso dos animais. MOREIRA et al. (2004), no entanto, observaram redução linear do ganho de peso de animais geneticamente superiores, ao se incrementar níveis de lisina na dieta $(0,75$ a 1,20\%). Essa diferença observada entre os trabalhos pode estar relacionada à linhagem utilizada, ao ambiente e ao padrão sanitário, uma vez que a ativação permanente ou temporária do sistema imunológico dos animais pode afetar as exigências de aminoácidos (WILLIAMS et al., 1997).

Em contraste aos resultados encontrados por KERR \& EASTER (1995), o desempenho dos suínos não foi alterado pela redução do teor de proteína em quatro unidades percentuais, exceto quando o nível de lisina digestível verdadeira foi reduzido para $0,7 \%$ que, comparado ao grupo-controle, resultou em menor $(\mathrm{P}<0,05)$ ganho de peso.

Com relação ao CRMD, de forma semelhante ao encontrado por ABREU et al. (2006), os níveis de lisina digestível não influenciaram essa variável ( $\mathrm{P}>0,05)$. No entanto, MOREIRA et al. (2004) observaram redução linear do consumo em função dos níveis crescentes de lisina. Em contrapartida,
TRINDADE NETO et al. (2005) observaram resposta quadrática para esta variável, indicando 1,015\% como o nível ótimo de lisina digestível. KERR et al. (2003) sugeriram que o desequilíbrio entre aminoácidos essenciais:não essenciais pode gerar aumento da energia líquida, devido ao maior catabolismo desses nutrientes no fígado, afetando, por conseqüência, o consumo voluntário pelos animais. No presente experimento, a alteração no consumo de ração foi observada.

Ainda que não tenham sido observados efeitos dos níveis de lisina sobre o GPMD e CRMD, o aumento dos níveis desse aminoácido proporcionou efeito linear decrescente $(\mathrm{P}<0,05)$ sobre a CA. Esses resultados foram semelhantes aos encontrados por SOUZA et al. (1999), que observaram uma resposta linear crescente entre a CA e o aumento dos níveis de lisina digestível até $0,83 \%$. Por outro lado, TRINDADE NETO et al. (2005) constataram efeito quadrático sobre essa variável. Nesses trabalhos, os melhores níveis de conversão alimentar foram obtidos com os níveis de 0,89\% e 1,015\% de lisina digestível verdadeira na ração, respectivamente. MOREIRA et al. (2004), no entanto, não observaram efeito dos níveis de lisina sobre a CA em animais pertencentes a grupos genéticos superiores, quando elevaram os níveis de lisina de 0,75 a 1,20\%. Estas variações ocorrem principalmente em função do grupo genético utilizado e das condições ambientais a que são submetidos os animais. No presente estudo, o efeito linear decrescente ocorreu devido ao pior ganho de peso observado nos animais que receberam dietas contendo o menor nível de lisina digestível verdadeira 
$(0,7 \%)$. Isso, de certa forma, contribuiu para uma maior diferença na conversão alimentar dos animais que receberam este nível de aminoácido em relação aos demais níveis. Este resultado reflete a importância da lisina como aminoácido limitante para o crescimento dos animais.

O aumento dos níveis de lisina em rações com reduzido teor de proteína bruta diminuiu $(\mathrm{P}<0,01)$ de forma linear a EULIS, sendo $07 \%$ o nível de LISD que representou o melhor resultado. Em outras palavras, o aumento da LISD não refletiu em melhora na sua utilização, já que não houve efeito direto sobre o GPMD $(\mathrm{P}>0,05)$.

Segundo PARTRIDGE et al. (1985) e BAKER (1996), a adição de alguns aminoácidos em excesso pode desequilibrar a síntese protéica em nível celular, devido a maior velocidade de absorção destes aminoácidos no trato gastrintestinal. Assim, a redução da proteína da dieta e a suplementação de alguns aminoácidos (no caso lisina, metionina e treonina) podem ter limitado a utilização dos demais aminoácidos, reduzindo a eficiência de utilização da lisina. Provavelmente, a eficiência poderia ter sido a mesma se houvesse também a suplementação com os demais aminoácidos, de acordo com o conceito de proteína ideal. No presente trabalho, foram adicionados apenas a metionina e a treonina, procurando manter a relação destes aminoácidos com a lisina. A EULIS pode representar uma efetiva utilização dos aminoácidos dietéticos para ganho muscular, já que o acúmulo de tecido adiposo exigirá maior consumo de nutrientes (inclusive aminoácidos) por unidade de ganho.

Com relação ao tratamento controle, a redução da proteína bruta e a variação dos níveis de lisina digestível de 0,7 a 1,3\% não afetaram $(\mathrm{P}>0,05) \mathrm{o}$ CRMD, a CA, a EULIS e a ET. Diversos trabalhos mostram que a redução da proteína bruta da ração em quatro unidades percentuais não afeta o desempenho (SHRIVER et al., 2003; ZANGERONIMO et al., 2006) e as características de carcaça (LE BELLEGO et al., 2002) dos animais, desde que suplementados com os principais aminoácidos limitantes (lisina, metionina e treonina). No presente trabalho, a variação dos níveis de lisina de 0,7 a 1,3 não foi suficiente para alterar estas variáveis estudadas.

Para RC e AOL houve efeito quadrático $(\mathrm{P}<0,05)$ dos níveis de lisina, sendo o nível de 1,03 e 1,00\% desse aminoácido, respectivamente, o que proporcionaram melhores resultados (Figuras 1 e 2). Quando comparados ao tratamento controle, os níveis de 0,9 e $1,1 \%$ de lisina digestível resultaram em maior RC $(\mathrm{P}<0,05)$, enquanto que apenas o nível de $1,1 \%$ desse aminoácido manteve a AOL em relação ao tratamento controle, com maior nível de proteína bruta. Estes resultados estão próximos ao preconizado por ROSTAGNO et al. (2005) e superiores ao recomendado pelo NRC (1998), cujos valores são de 1,03 e 0,83\%, respectivamente, para máximo desempenho dos animais. De acordo com SUSENBETH (1995), em muitos casos, quando a lisina se encontra disponível em quantidades insuficientes, a deposição de músculo encontra-se limitada. Por outro lado, o excesso de lisina também pode comprometer a utilização dos outros aminoácidos pela competição nos sítios de absorção ou de síntese. Isso explicaria o efeito quadrático dos níveis deste nutriente sobre o RC e a AOL.

Não se observou efeito $(\mathrm{P}>0,05)$ dos níveis de lisina sobre a ET. Entretanto, houve efeito quadrático $(\mathrm{P}<0,05)$ dos níveis desse aminoácido na RCG da carcaça, tendo o nível de 1,09\% apresentado melhor resultado. Em comparação ao grupo controle, observouse maior RCG nas carcaças dos animais alimentados com 1,1\%, indicando maior síntese protéica em relação à síntese lipídica nas carcaças dos animais. De acordo com TRINDADE NETO et al. (2004), a relação entre proteína e lipídeo é um indicativo da eficiência da síntese protéica em resposta ao nível de lisina na dieta. No presente experimento, o aumento na eficiência de utilização desse aminoácido, a partir da sua diminuição, não acompanhou o aumento da deposição de tecido magro nos animais, pelo fato de que a eficiência mensurada inclui também o uso de lisina para síntese de tecido adiposo. Além disso, a falta de outros aminoácidos pode ter limitado a utilização da lisina.

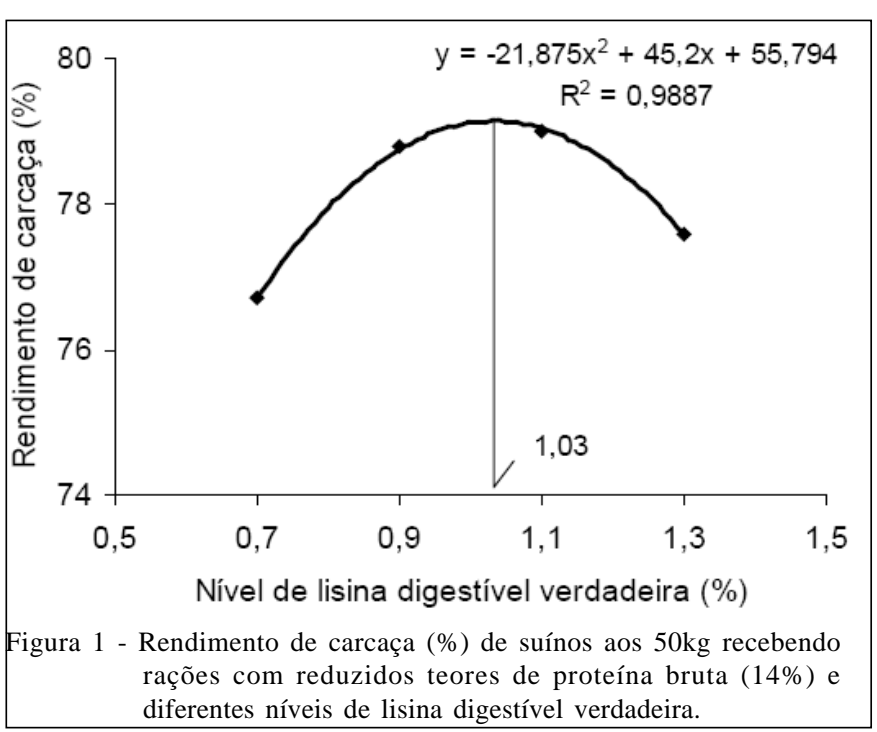

Ciência Rural, v.39, n.5, ago, 2009. 


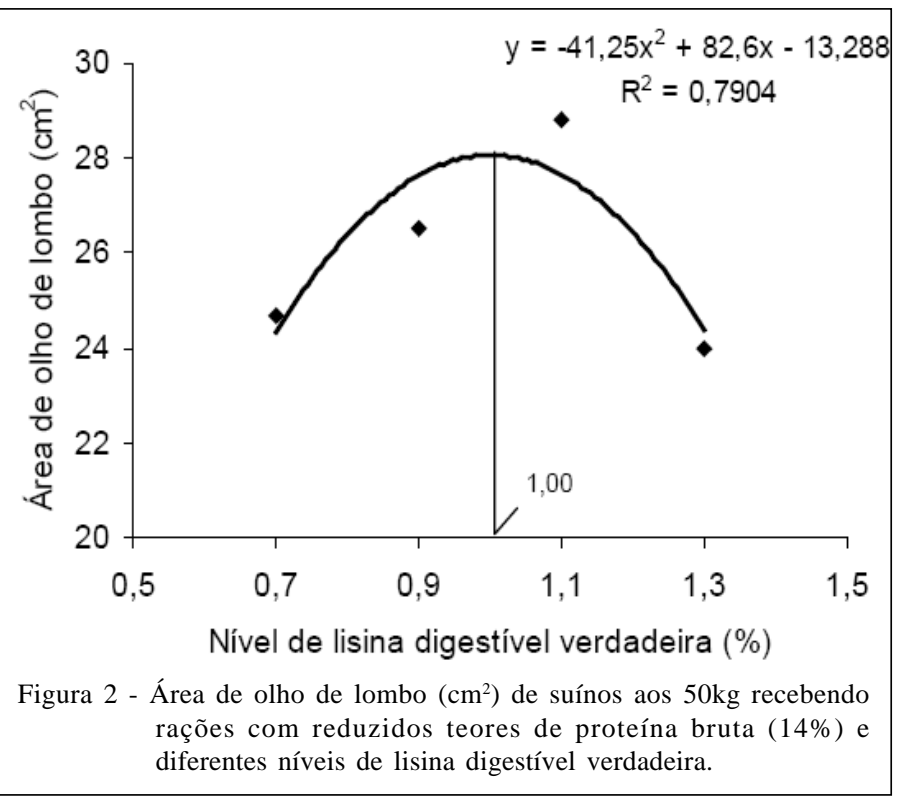

ABREU, M.L.T. et al. Níveis de lisina digestível em rações, utilizando-se o conceito de proteína ideal, para suínos machos castrados de alto potencial genético dos 15 aos $30 \mathrm{~kg}$. Revista Brasileira de Zootecnia, Viçosa, v.35, n.3, p.1039-1046, 2006. (supl.). Disponível em: $<$ h t t p : / / w w w. s c i e l o.b r / scielo.php?script $=$ sci_arttext \&pid=S1516$35982006000400014 \& \operatorname{lng}=$ en $\& n r m=$ iso $>$. Acesso em: 10 Jan. 2009. Doi: 10.1590/S151635982006000400014 .

BAKER, D.H. Advances in amino acid nutrition and metabolism of swine and poultry. In: KORNEGAY, E.T. (Ed.). Nutrient management of food animals to enhance and protect the environment. Boca Raton: CRC, 1996. p.41-53.

BATTERHAM, E.S.; BAYLEY, H.S. Effects of frequency of feeding diets containing free or protein-boud lysine on the oxidation of $\left[{ }^{14} \mathrm{C}\right]$ lysine or $\left[{ }^{14} \mathrm{C}\right]$ phenylalanine by growing pigs. British Journal of Nutrition, Wallingford, v.62, n.3, p.647-655, 1989.
Diversos trabalhos na literatura apontam o triptofano como quarto aminoácido mais limitante em dietas formuladas à base de milho e farelo de soja (LE BELLEGO et al. 2002; KERR et al., 2003).

Com relação à dieta controle, apenas o RC foi superior, quando houve redução do teor de proteína bruta. Isso sugere que, ao reduzir o teor deste nutriente, os níveis de lisina devem ser aumentados, mantendose o desempenho e a qualidade de carcaça dos animais de alto potencial genético.

\section{CONCLUSÃO}

O nível de 1,1\% de lisina digestível verdadeira em rações com reduzido teor de PB proporciona melhor rendimento de carcaça de suínos em crescimento sem, no entanto, afetar-lhes o desempenho. A redução do teor de proteína bruta, em quatro unidades percentuais, mantém o desempenho e a qualidade de carcaça, desde que mantidos os níveis dos principais nutrientes da dieta.

\section{AGRADECIMENTOS}

Os autores agradecem o apoio da Fundação de Amparo à Pesquisa do Estado de Minas Gerais (FAPEMIG)

\section{REFERÊNCIAS}

ABCS - ASSOCIAÇÃO BRASILEIRA DE CRIADORES DE SUÍNOS. Método brasileiro de classificação de carcaças. Estrela: ABCS, 1973. 17p. (Publicação Técnica nº 2).
BRIDI, A.M.; SILVA, C.A. Métodos de avaliação da carcaça e da carne suína. Londrina: Midiograf, 2006. V.1, 97p.

DE LA LLATA, M. et al. Effects of increasing L-lysine $\mathrm{HCl}$ in corn- or sorghum-soybean meal-based diets on growth performance and carcass characteristics of growing-finishing pigs. Journal of Animal Science, Champaign, v.80, p.24202432, 2002. Disponível em: < http://jas.fass.org/cgi/content/ full/80/9/2420>. On line. Acesso em: 10 Jan. 2009.

FERREIRA, D.F. Análises estatísticas por meio do Sisvar para Windows versão 4. 0. In: REUNIÃO ANUAL DA REGIÃO BRASILEIRA DA SOCIEDADE INTERNACIONAL DE BIOMETRIA, 45., 2000, São Carlos. Anais... São Carlos, SP: UFSCar, 2000. p.255-258.

FIRMAN, J.D.; BOLING, D. Ideal protein in turkeys. Poultry Science, Champaign v.77, n.1, p.105-110, 1998.

GASPAROTTO, L.F. et al. Exigência de lisina, com base no conceito de proteína ideal, para suínos machos castrados de dois grupos genéticos, na fase de crescimento. Revista Brasileira de Zootecnia, Viçosa, v.30, n.6, p.1742-1749, 2001. Disponível em: <http://www.scielo.br/ scielo.php ? script = sci_arttext\&pid=S 1516 $35982001000700012 \& \operatorname{lng}=$ en\&nrm $=$ iso $>$. Acesso em: 10 Jan. 2009. Doi: 10.1590/S1516-35982001000700012.

KERR, B.J.; EASTER, R.A. Effect feeding reduced protein amino acid-supplemented diets on nitrogen and energy balance in grower pigs. Journal of Animal Science, Champaign, v.73, n.10, p.3000-3008, 1995.

KERR, B.J. et al. Influences of dietary protein level, amino acid supplementation and environmental temperature on performance, body composition, organ weights and total heat production of growing pigs. Journal of Animal Science, Champaign, v.81, n.8, p.1998-2007, 2003. Disponível em: < http://jas.fass.org/cgi/content/full/81/8/1998>. On line. Acesso em: 10 Jan. 2009.

Ciência Rural, v.39, n.5, ago, 2009. 
LE BELLEGO, L. et al. Energy utilization of low-protein diets in growing pigs. Journal of Animal Science, Champaign, v.79, n.5, p.1259-1271, 2001. Disponível em: < http http:// jas.fass.org/cgi/reprint/79/5/1259>. On line. Acesso em: 10 Jan. 2009.

LE BELLEGO, L. et al. Effect of high temperature and lowprotein diets on performance of growing pigs. Journal of Animal Science, Champaign, v.80, n.3, p.691-701, 2002. Disponível em: < http://jas.fass.org/cgi/reprint/80/3/691.pdf >. On line. Acesso em: 10 Jan. 2009.

MOREIRA, I. et al. Exigência de lisina para suínos em crescimento e terminação, alimentados com rações de baixo teor de proteína, formuladas de acordo com o conceito de proteína ideal. Acta Scientiarum. Maringá, v.26, n.4, p.537542, 2004. Disponível em: <http://www.periodicos.uem.br/ojs/ index.php/ActaSciAnimSci/article/view/1760/1169>. On line. Acesso: 10 jan. 2009.

NATIONAL RESEARCH COUNCIL. Nutrient requirements of swine. 10.ed. Washington: National Academy of Sciences, 1998. 212p.

OLIVEIRA, A.L.S. et al. Lisina em rações para suínos machos castrados selecionados para deposição de carne magra na carcaça dos 110 aos $125 \mathrm{~kg}$. Revista Brasileira de Zootecnia, Viçosa, v.32, n.1, p.150-155, 2003. Disponível em: <http:// www.scielo.br/scielo.php?script=sci_arttext\&pid=S1516 35982003000100019\&lng $=$ en \&nrm=iso $>$. On line. Acesso: 10 Jan. 2009. Doi: 10.1590/S1516-35982003000100019.

OLIVEIRA, V. et al. Características de carcaça e peso de vísceras em suínos alimentados com rações contendo baixos teores de proteína bruta. Ciência Rural, Santa Maria, v.36, n.6, p.18901895, 2006. Disponível em: <http://www.scielo.br/ s c i elo.php? s cript = sci_arttext \& pid = S 0103 $84782006000600035 \& \operatorname{lng}=\mathrm{en} \& \mathrm{nrm}=\mathrm{iso}>$. On line. Acesso em: 10 Jan. 2009. Doi: 10.1590/S0103-84782006000600035.

PARTRIDGE, I.G. et al. A note on the effect of feeding frequency on nitrogen use in growing boars given diets with varying levels of lysine. Animal Production, Edingurgh, v.40, n.2, p.375377, 1985.

ROSTAGNO, H.S. et al. Tabelas brasileiras para aves e suínos: composição de alimentos e exigências nutricionais. 2.ed. Viçosa: UFV, 2005. 186p.
SHRIVER, J.A. et al. Effects of adding fiber sources to reducedcrude protein, amino acid-supplemented diets on nitrogen excretion, growth performance and carcass traits of finish pigs. Journal of Animal Science, Champaign, v. 81, n.2, p. $492-$ 502, 2003. Disponível em: < http://jas.fass.org/cgi/content/ full/81/2/492>. On line. Acesso em: 10 Jan. 2009.

SOUZA, A.M. et al. Exigências nutricionais de lisina para suínos mestiços, de 30 a $60 \mathrm{~kg}$ de peso. In: REUNIÃO ANUAL DA SOCIEDADE BRASILEIRA DE ZOOTECNIA, 36., 1999, Porto Alegre. Anais... Porto Alegre: UFRGS, 1999. p.227.

SUSENBETH, A. Factors affecting lysine utilization in growing pigs: an analyses of literature data. Livestock Production Science, v.43, p.193, 1995.

TRINDADE NETO, M.A. et al. Níveis de lisina para leitões na fase inicial-1 do crescimento pós-desmame: composição corporal aos 11,9 e 19,0kg. Revista Brasileira de Zootecnia, Viçosa, v.33, n.6, p.1777-1789, 2004. (Supl., 1). Disponível em: < http://www.scielo.br/scielo.php?script=sci_arttext\&pid=S151635982004000700016>. On line. Acesso: 10 Jan. 2009

TRINDADE NETO, M.A. et al. Energia metabolizável e lisina digestível para suínos na fase de crescimento, criados em condições de segregação sanitária. Revista Brasileira de Zootecnia, Viçosa, v.34, n.6, p.1980-1989, 2005. Disponível em: <http:// www.scielo.br/scielo.php?script $=$ sci_arttext\&pid $=$ S151635982005000600023\&lng=en\&nrm=iso>. Acesso em: $10 \mathrm{Jan}$. 2009. Doi: 10.1590/S1516-35982005000600023.

WILLIAMS, N.H. et al. Effect of chronic immune system activation on the rate, efficiency, and composition of growth and lysine needs of pigs fed from 6 to $27 \mathrm{~kg}$. Journal of Animal Science, Champaign, v.75, n.9, p.2463-2471, 1997. Disponível em: < http://jas.fass.org/cgi/content/abstract/75/9/ 2463>. N line. Acesso em: 10 Jan. 2009.

ZANGERONIMO, M.G. et al. Redução do nível de proteína bruta da ração suplementada com aminoácidos sintéticos para leitões na fase inicial. Revista Brasileira de Zootecnia, Viçosa, v.35, n.3, p.849-856, 2006. Disponível em: <http:// www.scielo.br/scielo.php?script $=$ sci_arttext\&pid=S1516$5982007000600022 \& \operatorname{lng}=\mathrm{e} \& \mathrm{nrm}=\mathrm{iso} \& \operatorname{lng}=\mathrm{e}>$. On line. Acesso: 10 jan. 2009. Doi:10.1590/S151635982007000600022 . 